University of Nebraska - Lincoln

DigitalCommons@University of Nebraska - Lincoln

Pinworm research in the Southwest USA: Five decades of methodological and theoretical development and the epidemiological approach

Morgana Camacho

Karl Reinhard

Follow this and additional works at: https://digitalcommons.unl.edu/natresreinhard

Part of the Archaeological Anthropology Commons, Ecology and Evolutionary Biology Commons, Environmental Public Health Commons, Other Public Health Commons, and the Parasitology Commons

This Article is brought to you for free and open access by the Natural Resources, School of at DigitalCommons@University of Nebraska - Lincoln. It has been accepted for inclusion in Karl Reinhard Papers/ Publications by an authorized administrator of DigitalCommons@University of Nebraska - Lincoln. 


\title{
Pinworm research in the Southwest USA: Five decades of methodological and theoretical development and the epidemiological approach
}

\author{
Morgana Camacho ${ }^{1} \&$ Karl J. Reinhard ${ }^{2}$ \\ 1 Escola Nacional de Saúde Pública Sergio Arouca, Fundação Oswaldo Cruz, \\ Rio de Janeiro, Brazil \\ 2 Pathoecology Laboratory, School of Natural Resources, University of \\ Nebraska-Lincoln, Lincoln, NE, USA \\ Correspondence: Morgana Camacho, morganacamacho88@gmail.com
}

\begin{abstract}
Pinworms infected Ancestral Pueblo populations since early periods of occupation on the Colorado Plateau. The high prevalence of pinworm found in these populations was correlated with the habitation style developments through time. However, in previous studies, Turkey Pen Cave, an early occupation site, and Salmon Ruins, a late occupation site, exhibited prevalences that were anomalously low, suggesting that these sites were outliers. Alternatively, it is possible that the previous quantification method was not successful in detecting the real prevalence and eggs per gram, which led to inexact interpretations. The aims of this study were to verify if previous pinworm prevalences for Turkey Pen Cave and Salmon Ruins were underestimated. In addition, new analyses were added to the data set. Two latrines from Aztec Ruins, a Pueblo III occupation never studied before, were sampled and studied. We applied the pathoecology concept and descriptive/comparative parasitological statistical parameters. Human coprolites were weighed and rehydrated along with
\end{abstract}

Published in Archaeological and Anthropological Sciences 12 (2020), 63, 10pp.

DOI: $10.1007 / \mathrm{s} 12520-019-00994-2$

Copyright (c) 2020 Springer-Verlag GmbH Germany. Used by permission.

Submitted 31 December 2018; accepted 16 October 2019; published 1 February 2020. 
introduced exotic Lycopodium tablets and screened through $250-\mu m m e s h$. Parasite eggs and Lycopodium spores were quantified and eggs per gram were estimated for each sample. Parasitological statistical parameters were calculated at Quantitative Parasitology 3.0 software. Pinworm was the only parasite recovered in all sites. The prevalences observed in early and late occupation sites refute previous correlation with habitation style. This study indicates that the previously estimated prevalences were underestimated, which interfered in the accurate interpretation on Ancestral Pueblo pinworm infection. This study reveals a new paleoparasitological panorama of pinworm infection in Ancestral Pueblo populations.

Keywords: Pinworm, Paleoepidemiology, Quantification, Ancestral Pueblo

\section{Introduction}

Parasitologists have long studied archeological remains in the arid west of North America (Bryant and Reinhard 2012; Fry 1977, 1980a, b; Fry and Hall 1969; Fry and Moore 1969; Hugot et al. 1999; Moore et al. 1969; Morrow and Reinhard 2016, 2018; Reinhard 2008a, b; Reinhard and Bryant 2008; Reinhard et al. 1987). Throughout these five decades, research has focused on the ecology of human-parasite interaction. Distinct periods are represented in this development, beginning with an early exploration period, followed by geographical comparison of infections and concluding with an archeology/parasitology synthesis in the form of pathoecology (Reinhard and Araujo 2012). Most recently, the epidemiological significance of infection was established by applying the pathoecology concept (Camacho et al. 2018a; Morrow and Reinhard 2018; Reinhard and Bryant 2008). Pathoecology is the study of the environmental and cultural factors that influence infections and disease emergence (Reinhard 1974; Reinhard and Bryant 2008). The application of this concept contributes to the interpretation of the ecological factors involved in the manifestation and maintenance of infections in ancient populations. Along with pathoecology, parasitology started to apply quantification methods so it can improve the interpretative potential of the parasitological evidence (Camacho et al. 2018a; Reinhard 2017). However, quantification methods are only applicable in archeological sites that exhibit excellent preservation conditions. Fortunately, archeological sites in the North American deserts often present exceptional preservation conditions and offer the opportunity to verify the epidemiological meaning of infection in these populations (Fugassa et al. 2011; Reinhard 2008a, b). 
Furthermore, with these data, there is a potential to connect the epidemiology of ancient populations' infections with modern epidemiological data. In this way, we can compare and contrast the infection of ancient people with those of modern people. Thus, we can envisage the parasite patterns of ancient people who have subsistence and technology unlike any existing peoples today. This can be important to help predict epidemiological sceneries related to the emergence or reemergence of infections in modern populations.

Parasites usually exhibit an aggregated distribution in host populations (Crofton 1971). Parasite aggregation is characterized when most hosts present very low parasite burdens and few hosts present very high burdens (Shaw et al. 1998). The most common way to verify parasite distribution is to calculate the variance to mean ratio (VMR), which is a measure used to quantify if a set of observed occurrences is aggregated or dispersed, compared with a standard statistical model (Rózsa et al. 2000). This estimative is the statistical parameter used to compare ancient with modern parasitological data (Rácz et al. 2015; Reinhard and Buikstra 2003). If ancient parasite distribution is also found to be aggregated, then we can consider that both epidemiological scenarios are probably equivalent and present similar determinants of infection (Reinhard and Buikstra 2003). In this study, we are applying this approach as we attempt to demonstrate that archeological data can be comparable with contemporary epidemiological data to reveal unique ancient patterns of transmission.

Pinworm is a common parasite in Ancestral Pueblo populations (Reinhard et al. 2016). Variable prevalences were observed in sites from early (Basketmaker II-O to $400 \mathrm{AD}$ ) to late (Pueblo III-1020 to 1350 AD) occupations, which were associated by Hugot et al. (1999) with the architecture styles used by these populations through time. The researchers' hypothesis was that small villages with no stonewall constructions (Basketmaker II) would have the lowest pinworm prevalences, whereas large villages with stonewall constructions inside caves (Pueblo III) would have the highest (Hugot et al. 1999). In previous studies, Turkey Pen Cave, located in Grand Gulch, Utah, a Basketmaker II site had $29 \%$ of pinworm prevalence. Salmon Ruins, located in Bloomfield, New Mexico, a Pueblo II to Pueblo III site, presented $8 \%$ of pinworm prevalence. These sites' architecture style and the pinworm prevalences observed indicate that they represent a contrast to Hugot et al.'s (1999) hypothesis (Reinhard 2008a). 
The estimation of prevalence of infection can be achieved by applying a quantification method that allows not only to assess this parameter but also to calculate eggs per gram (EPG). Thus, it is possible to apply parasitological statistics in order to study the impact of infection on ancient populations (Reinhard and Buikstra 2003). The quantification method applied in all Ancestral Pueblo sites involved the addition of Lycopodium tablets and the microscopic analyses in which parasite eggs and spores were quantified (Camacho et al. 2018a). Previous studies counted 25 Lycopodium spores to standardize quantification (Reinhard 1992). The goal of this approach was to identify infections likely to have provoked symptoms. After reaching this number of spores, coprolite analysis was considered complete, and the sample was identified as positive or negative for parasites and likely to have associated symptoms. More recently, as the pathoecological approach emerged, the analysis goal was to identify all infections requiring the counting of more spores. Morrow (2016) tested different minimum values of Lycopodium spore quantification (25, 50, 100, 200, and 500) in order to verify the accuracy of the diagnosis. She observed that samples quantified using 25, 50, and 100 minimum values of $L y$ copodium spores yielded differences in the number of positive and negative samples for parasite egg. However, when quantification was based on 200 and 500 minimum spore counts, the same values of positive and negative samples were reported. Positive and negative sample values are translated into frequency of infection/prevalence estimation. Since counting both 200 and 500 spores obtained the same prevalence estimation accuracy, Morrow (2016) suggested a minimum count of 200 Lycopodium spores. Based on Morrow's (2016) conclusion, we hypothesized that previous pinworm prevalence estimation for Ancestral Pueblo populations are underestimated (Reinhard 1992).

Considering these arguments, in this study we verify if previous pinworm prevalences of infection in Turkey Pen Cave and Salmon Ruins were underestimated, by applying the minimum of 200 Lycopodium spore quantification method in the same samples analyzed in previous studies. We also verify parasite infection in two latrines of Aztec Ruins (rooms 219 and 225), a Pueblo III occupation site never studied before. With the data obtained, we investigate the pathoecology of pinworm infection in these sites and apply descriptive and comparative parasitological statistical parameters, including the VMR 
estimation in order to discuss the epidemiological impact of pinworm infection in these populations and the possible comparison with contemporary epidemiological data.

\section{Materials and methods}

Human coprolites from three Ancestral Pueblo archeological sites, dated from different periods, were analyzed in the present study. Sample selection was based on criteria established by Reinhard (2008a) and later discussed by Reinhard (2017) and Camacho et al. (2018a) to diversify coprolites in sites with latrines that contain large amounts of samples, which is the case for the sites studied in this research. These authors explain that when sites have large amounts of coprolites preserved in latrine environments, one can obtain samples from different proveniences and, in this way, increase the chances of selecting coprolites from different individuals. The definition of provenience is based on different strata, levels, and grid squares identified during excavations. In order to be sure that diversified samples were collected in this study so population parasitological parameters could be estimated, for example prevalence, sample selection was performed according to these criteria.

Turkey Pen Cave is a rock shelter located in Grand Gulch, Utah (Fig. 1). It represents the first period of Ancestral Puebloan occupation, known as Basketmaker II, and it is dated between 73 and 181 AD. The Ancestral Puebloan population living in Turkey Pen Cave was already relying on maize horticulture as the main diet source (Matson and Chisholm 1991). From this site, thirteen coprolites were analyzed. Salmon Ruins and Aztec Ruins (Fig. 1) represent a more recent period of occupation and were built by the Chaco Culture between 1000 and 1200 years AD, when the Late Pueblo II and Early Pueblo III were present in this region (Vivian and Hilpert 2012).

Salmon Ruins is a Chaco outlier community located by the San Juan River, in Bloomfield, New Mexico. It is composed by several small ruins and a Great House that had 150 rooms in the ground floor and nearly 100 rooms on the second floor (Fig. 2). It was built between 1088 and $1100 \mathrm{AD}$ and abandoned by the Chaco occupation around 1130 AD (Vivian and Hilpert 2012). A second Mesa Verde Ancestral 

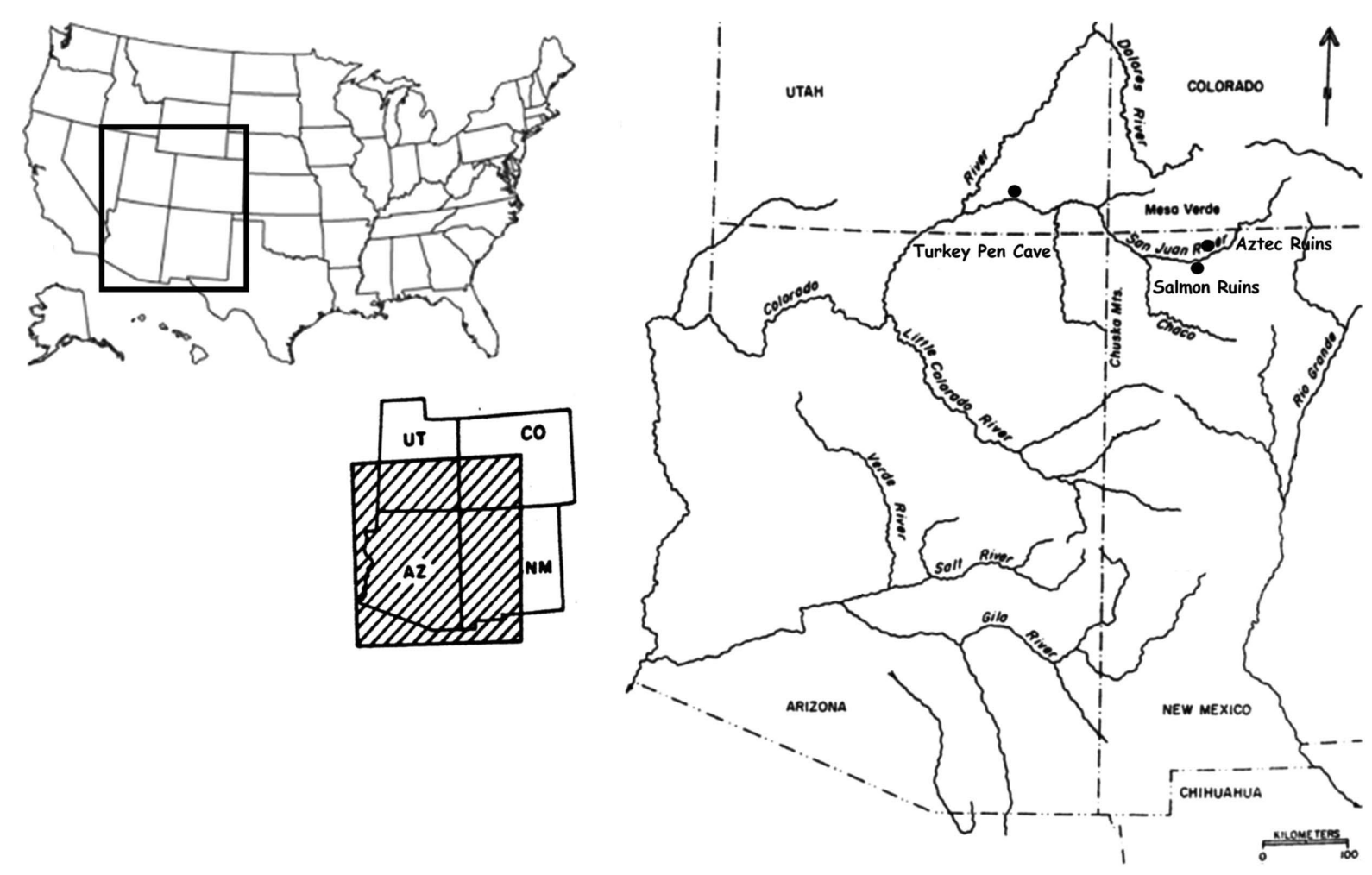

Fig. 1 Map demonstrating the geographical location of Turkey Pen Cave, Salmon Ruins, and Aztec Ruins. Modified from Doyel (1992).

Puebloan occupation began at 1180 AD. This population remodeled most of the Great House construction and used it as burial place, storage, ritual place, and latrine (Vivian and Hilpert 2012). For this study, 67 coprolites were collected from the only remaining latrine, room $62 \mathrm{~W}$.

Aztec Ruins is the largest Chaco outlier community, and it is located in the junction of the San Juan and Animas Rivers, in Aztec, New Mexico. It is a complex of ruins, in which the West Ruin, a Great House with 400 rooms is the best studied and excavated (Fig. 3). For reasons that are not clear, the Chaco population abandoned Aztec Ruins by $1275 \mathrm{AD}$ and a subsequent occupation by a Mesa Verde population is evidenced by ceramics and burials. The Mesa Verde population used the West Ruin as a burial, storage, ritual place, and latrine (Vivian and Hilpert, 2012). Until now, archeologists found two latrines, rooms 219 and 225, from which 21 and 22 coprolites were collected, respectively. In this study, samples from these latrines were analyzed separately, as 


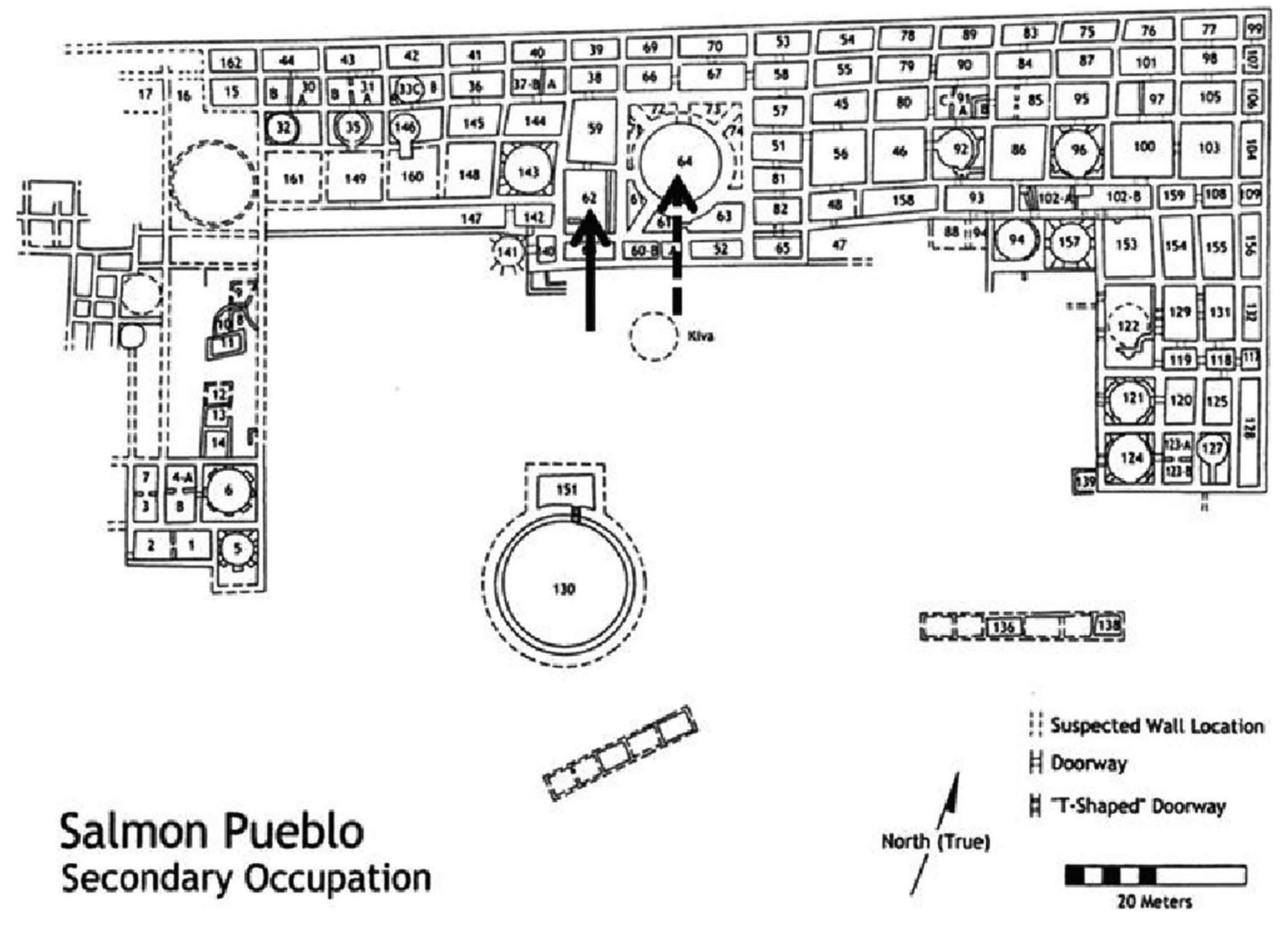

Fig. 2 Schematic drawing of Salmon Ruins Great House at the second period of occupation. The black arrow indicates the only remain latrine, room $62 \mathrm{~W}$. The dotted arrow indicates the location of the elevated kiva. Source: San Juan County Archeological Research Center and Library.

representative of two populations, since taphonomic conditions and dietary data point to different preservation and food consumption in these latrines that suggest that they were used by different groups or populations (Camacho et al. 2018b; Reinhard et al. 2019).

Individual protection equipment and disposable material were used to collect coprolites individually in order to avoid contamination. Coprolites were stored in individual airtight plastic bags in environmental temperature and transported to the Pathoecology Lab, School of Natural Resources, University of Nebraska-Lincoln, USA. Since coprolites are a unique evidence, there is always a concern about the conservation of part of the sample so that it can be preserved for future analyses. When possible, the standard amount of sample analyzed in ancient parasitological analyses is $5 \mathrm{~g}$ (Dufour and Le Bailly 2013). This amount of sample is considered for larger coprolites, in which part of 


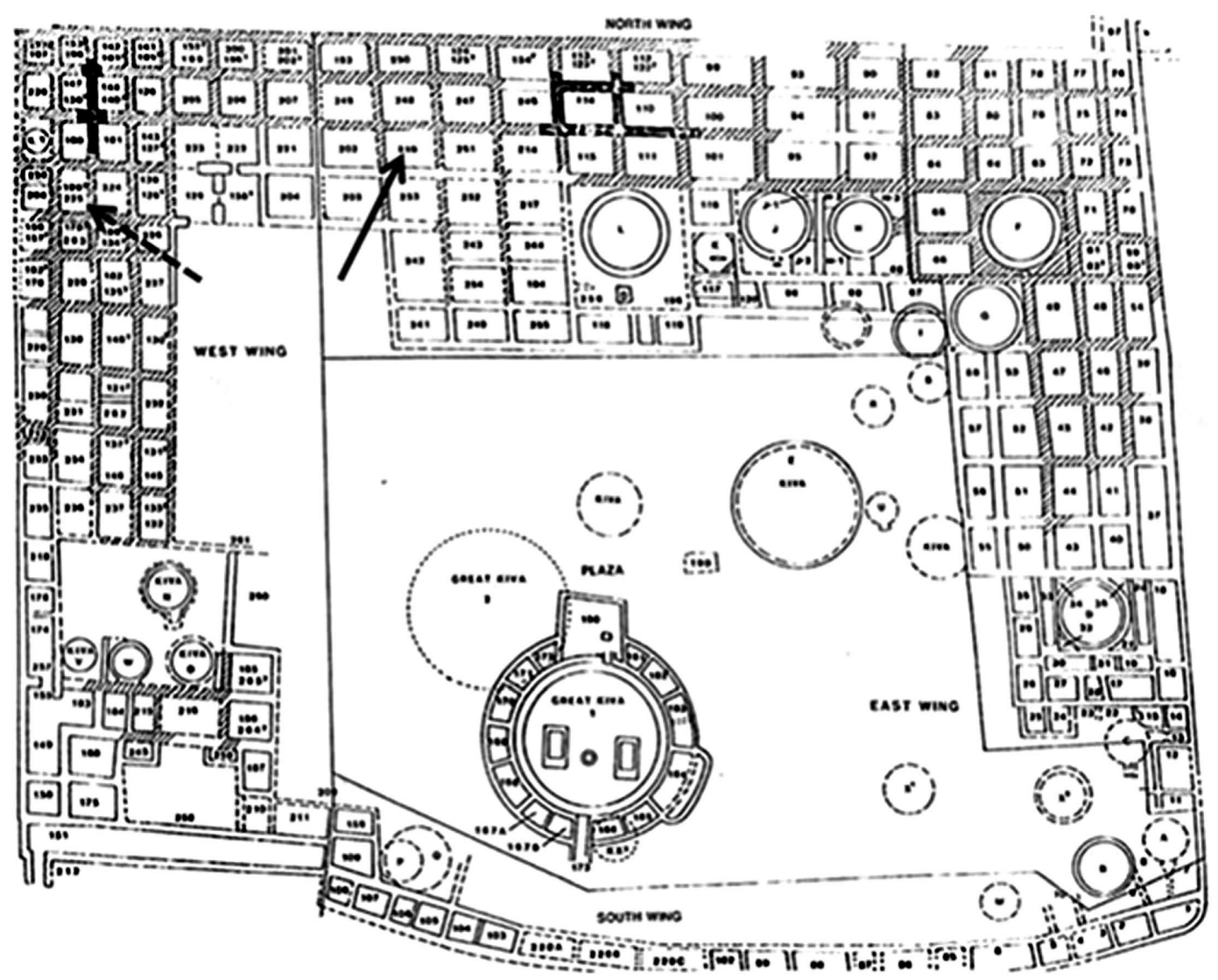

Fig. 3 Schematic drawing of Aztec RuinsWest Ruin. The black arrow indicates the location of the first latrine, room 219. The dotted arrow indicates the location of the second latrine, room 225. Source: Aztec Ruins National Monument New Mexico.

the sample can be conserved after processing $5 \mathrm{~g}$. However, in some occasions, it is not possible to analyze this amount of sample simply because some coprolites collected have less than $5 \mathrm{~g}$ preserved. In these cases, samples between 1 and $4 \mathrm{~g}$ are analyzed, depending on the total amount of coprolite (Fugassa 2011; Reinhard et al. 1986). In this study, when possible, 5-g samples were processed; however, 1-4-g samples were selected in cases where coprolites had smaller weights. Part of each coprolite was conserved for future analyses, and these remaining samples are stored in the Pathoecology Lab, School of Natural Resources, University of Nebraska-Lincoln, USA.

When applying the quantification method based on the introduction of Lycopodium spores, Reinhard (2008a) used one tablet, containing approximately 12,500 spores, for each gram of coprolite processed. In 
this study, the same method was applied. After weighing the samples and transferring them to 50-ml plastic tubes with screw caps, 1 Lycopodium tablet (batch no. 12496) was added to 1-g samples, two tablets were added to 2-g samples, three tablets were added to 3-g samples, four tablets were added to 4 -g samples, and five tablets were added to 5-g samples. Coprolites were then rehydrated in $0.5 \%$ trisodium phosphate $\left(\mathrm{Na}_{3} \mathrm{PO}_{4}\right)$ aqueous solution, enough to cover the samples inside the tubes, during $24 \mathrm{~h}$ (Callen and Cameron 1960). Two hundred microliters of $40 \%$ hydrochloric acid $(\mathrm{HCl})$ were added to enable the tablets and some of the mineralized coprolites to dissociate (Reinhard et al. 2008).

After the rehydration process, each sample was vortexed during 40 $s$ and immediately poured through a $250-\mu \mathrm{m}$ mesh placed in a $50-\mathrm{ml}$ beaker, in order to separate the macro- from the micro residues. Distilled water and a metal spatula were used to disaggregate the macro residues in the mesh. Alcohol was added to avoid microorganism proliferation. The macro residues were dried at room temperature. After this process, each sample macro residue was stored in individual Whirl- Pak® plastic bags for dietary analyses (Reinhard et al. 2019). The micro residues in the beakers were pipetted into $50-\mathrm{ml}$ graduated plastic tubes with screw caps. Drops of each sample were pipetted to microscope slides, mixed with glycerin and cover slipped. The slides were analyzed at $\times 100$ and photographs were taken at $\times 400$ magnification. A minimum of 200 Lycopodium spores was quantified for each sample, along with any parasite eggs found during these analyses (Morrow 2016).

To calculate the EPG of coprolite, we applied the following formula (modified for parasite eggs) (Pearsall 2016): $\mathrm{EPG}=[(p / m) \times a] / v$, where $p$ is the number of parasite eggs counted, $m$ is the number of Lycopodium spores counted, $a$ is the number of Lycopodium spores added, and $v$ is the quantity of sample processed. Descriptive and comparative statistics were calculated at the Quantitative Parasitology 3.0 software by using the parameters described and recommended by Reiczigel and Rózsa (2005) and Rózsa et al. (2000). For descriptive statistics, prevalence, mean intensity, median intensity, mean abundance, and VMR were calculated (Rózsa et al. 2000). The prevalence indicates the proportion of positive samples in all coprolites analyzed. The mean intensity indicates the mean number of parasite eggs found in the positive coprolites. The median intensity indicates the median 
number of parasite eggs found in the positive coprolites. The mean abundance indicates the mean number of parasite eggs found in all coprolites (Rózsa et al. 2000).

To estimate the parasite distribution in each site (population), VMR was calculated, and the results were interpreted as follows (Bush et al. 1997; Ludwig and Reynolds 1988): VMR < 1, under dispersed (binomial distribution); VMR $=0$, not dispersed (constant random variable); VMR = 1, Poisson distribution; and VMR > 1, aggregated distribution. Prevalence comparisons between all sites were made by using $\chi^{2}$ and Fisher's exact test $(P<0.05)$. Prevalence was also compared between each site (one site with the other) by using the same statistical tests. Comparison between these groups' mean intensities and mean abundances was made by applying the Bootstrap test $(P<0.05)$, and comparison between the median intensities observed was made by applying Mood's median test $(P<0.05$ ) (Reiczigel and Rózsa 2005; Rózsa et al. 2000). The Bootstrap test of mean intensities and mean abundances was made by comparing one site with the other. The Mood's median test was made by comparing all median intensities observed in the sites (Rózsa et al. 2000).

\section{Results}

The results indicate that Ancestral Puebloans from all the sites studied were infected by Enterobius vermicularis and only by this helminth parasite. Descriptive statistics for each site is demonstrated in Table 1. In Turkey Pen Cave, five of 13 samples were positive, representing $38.5 \%$ of the prevalence. In Salmon Ruins, 22 (32.8\%) of 67 samples had pinworm eggs. In Aztec Ruins room 219, only 3 (14.3\%) of the 21 samples were positive, the lowest prevalence found. The higher prevalence (72.7\%) was observed in Aztec Ruins room 225, where 16 of 22 samples were positive. The EPG values indicated a high number of eggs in some samples compared with most of the other coprolites analyzed (Fig. 4).

A statistical comparison of prevalences of infection indicates that there is a statistically significant difference between the prevalences of all of the studied sites ( $\chi^{2}$ and Fisher's exact tests, $P=0.00$ ). The comparison of the prevalence between the Ancestral Pueblo populations indicated statistically significant differences for some sites. 
Table 1 Descriptive statistics calculated for Turkey Pen Cave, Salmon Ruins, Aztec Ruins room 219, and Aztec Ruins room 225 sites (populations), including prevalences, mean intensity, median intensity, mean abundance, and VMR concerning pinworm infection

Data

\begin{tabular}{rrrr}
\hline \multicolumn{4}{c}{ Sites } \\
$\begin{array}{r}\text { Turkey } \\
(n=13)\end{array}$ & $\begin{array}{r}\text { Salmon } \\
\text { Ruins } \\
(n=67)\end{array}$ & $\begin{array}{r}\text { Aztec Ruins } \\
\text { Room } 219 \\
(n=21)\end{array}$ & $\begin{array}{r}\text { Aztec Ruins } \\
\text { Room 225 } \\
(n=22)\end{array}$ \\
$38.5 \%$ & $32.8 \%$ & $14.3 \%$ & $72.7 \%$ \\
494.93 & 701 & 138.92 & 403.54 \\
93.0 & 166.5 & 61.0 & 145.0 \\
190.492 & 230.179 & 19.857 & 293.545 \\
943.03 & 3961.29 & 708.29 & 216.87 \\
\hline
\end{tabular}

$V M R$, variance to mean ratio

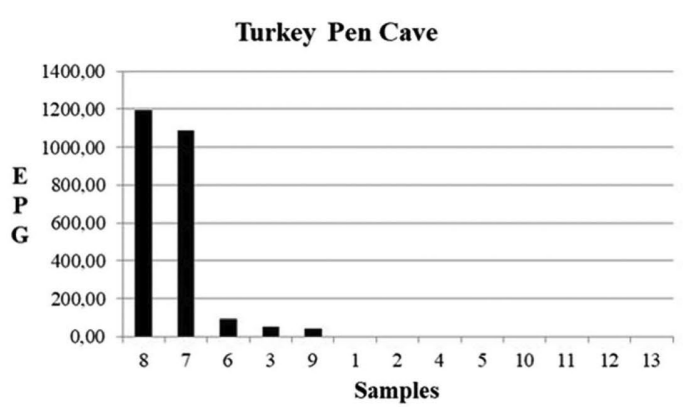

Aztec Ruins-Room 219

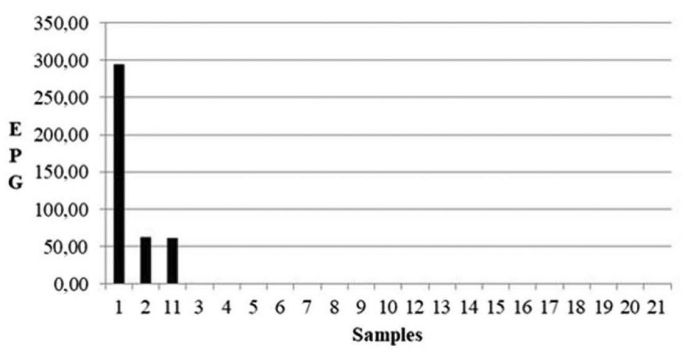

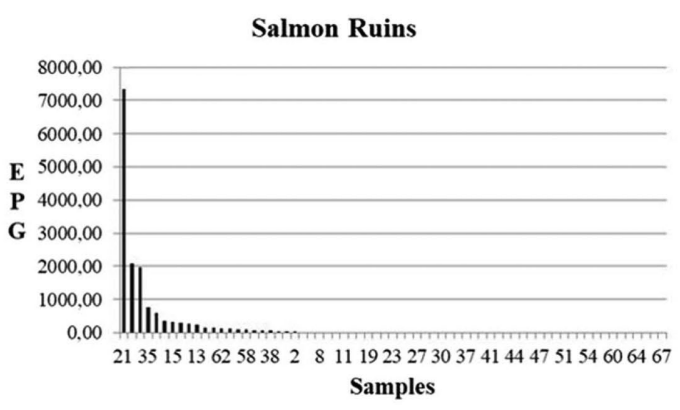

Aztec Ruins-Room 225

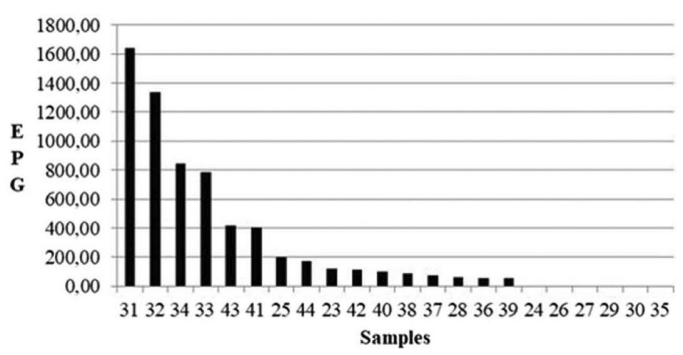

Fig. 4 EPG estimated for Turkey Pen Cave, Salmon Ruins, Aztec Ruins room 219, and Aztec Ruins room 225 coprolite samples.

Aztec Ruins room 225 prevalence was higher when compared with Aztec Ruins room 219 and Salmon Ruins ( $\chi^{2}$ and Fisher's exact test, $P=$ 0.00), but not with Turkey Pen Cave $\left(\chi^{2}, P=0.05\right.$; Fisher's exact test, $P=0.07)$. Comparisons between Salmon Ruins and Turkey Pen Cave $\left(\chi^{2}, P=0.69\right.$; Fisher's exact test, $\left.P=0.75\right)$ and Salmon Ruins and Aztec Ruins room $219\left(\chi^{2}, P=0.10\right.$; Fisher's exact test, $\left.P=0.16\right)$ prevalences indicated no statistical difference. 
When comparing the results of mean intensity, no statistical significant difference was found. The $P$ values obtained were the following: $P=0.65$ for Salmon Ruins and Turkey Pen Cave; $P=0.45$ for Salmon Ruins and Aztec Ruins room 225; $P=0.27$ for Salmon Ruins and Aztec Ruins room 219; $P=0.74$ for Aztec Ruins room 225 and Turkey Pen Cave; $P=0.19$ for Aztec Ruins room 219 and Turkey Pen Cave; and $P=0.10$ for Aztec Ruins room 219 and Aztec Ruins room 225. This means that the number of parasite eggs was not significantly different when comparing the positive coprolites found in each site.

The comparison between the mean abundances was also not statistically significant. The $P$ values obtained for each analysis were the following: $P=0.82$ for Salmon Ruins and Turkey Pen Cave; $P=0.68$ for Salmon Ruins and Aztec Ruins room 225; $P=0.23$ for Salmon Ruins and Aztec Ruins room 219; $P=0.51$ for Aztec Ruins room 225 and Turkey Pen Cave; $P=0.15$ for Aztec Ruins room 219 and Turkey Pen Cave; and $P=0.05$ for Aztec Ruins room 219 and Aztec Ruins room 225. This means that the number of parasite eggs found in each site was not significantly different when comparing all the coprolites analyzed. The comparison between all median intensities was also not statistically significant $(P=0.93)$. This means that the typical level of infection was not significantly different when comparing the positive coprolites found in each site. Parasite distribution analysis showed substantial aggregation in all archeological sites. Results demonstrated that VMR values were considerably greater than 1 for all sites (Table 1).

\section{Discussion}

This study demonstrates the highest prevalences of pinworm infection found in the Ancestral Puebloan populations. The prevalences observed in Turkey Pen Cave (38.5\%) and Salmon Ruins (32.8\%) were higher than the ones observed in previous studies, especially for Salmon Ruins. These results corroborate with the hypothesis that previous pinworm prevalence estimation for Ancestral Pueblo populations are underestimated due to the quantification method applied which established a minimum of 25 Lycopodium spores to count. Since this hypothesis was confirmed, it is important to reevaluate this epidemiological scenario for all previously analyzed Ancestral 
Pueblo sites in order to establish the real impact of intestinal parasite infections in these populations.

This analysis supports the previous conclusion that Ancestral Pueblo people were heavily infected with pinworm. The standard technique applied to diagnose pinworm infection is the cellophane tape pressed against the perianal region and analyzed under a light microscope. Pinworm females deposit very few eggs in the host intestine, so fecal analysis usually results in false negatives (Roberts et al. 2013). Only $5 \%$ to $10 \%$ of the individuals parasitized with E. vermicularis show eggs in their feces (Rey 2008; Roberts et al. 2013). In the present study, even with the parasitological analysis of ancient fecal samples, the prevalences significantly exceeded the values found in the fecal samples from contemporary parasitized individuals. This demonstrates that the sample processing and quantification methods applied in this study were efficient in recovering parasite eggs from ancient samples and estimating the impact of parasite infection in these populations. Therefore, we recommend the use of these methods to recover data for epidemiological studies of ancient populations.

Descriptive and comparative statistical parameters calculated for all sites demonstrate that for most patterns of infection, the sites' populations were equally highly infected. To interpret these statistical data, it is also important to consider factors that interfere in parasite information, such as taphonomy (Morrow et al. 2016; Camacho et al. 2018b). The sites studied are located in arid areas that explain excellent preservation in most of them. Turkey Pen Cave is characterized by a rock shelter which is an environment considered to be the best to preserve micro residues such as parasite eggs; therefore, its prevalence estimation and other statistical parameters calculated probably correspond to the reality found in ancient times. However, as demonstrated by Camacho et al. (2018b), coprolites from the Great Houses Salmon Ruins and Aztec Ruins room 225 presented excellent egg preservation, but parasite eggs in coprolites from Aztec Ruins room 219 were badly preserved, representing a variation on preservation in these sites. According to the authors, mite predation was probably the main responsible for the low prevalence found in Aztec Ruins room 219. The degradation of the eggs consequently influenced the prevalence estimation and the calculation of the other statistical parameters. Nevertheless, the prevalence found in Aztec Ruins room219 is considered high when compared with the usually 
$5 \%$ to $10 \%$ of modern parasitized individuals that present pinworm eggs in their feces.

The high prevalence is especially remarkable when one considers that pinworm eggs rapidly die in arid environments such as the deserts of western North America. Experimental hatching of eggs after exposure to aridity provided these data: 6-h drying resulted in 67\% viability, $12 \mathrm{~h}$ produced 53\% viability, 24 h produced $33 \%$ viability, 2 days produced $22 \%$ viability, 3 days produced $15 \%$ viability, and 5 days produced o\% viability (Hulínská 1974). Pinworms retain higher viability in humid climates and are susceptible to desiccation-induced egg death in aridity. In arid climates, pinworm eggs need to achieve infection before inevitable desiccation. Therefore, the Pueblo persistent pinworm parasitism had to have involved infection that overcame in some way the egg susceptibility to desiccation.

Both Basketmaker II (o-400 AD) and Pueblo III (1020- 1350 AD) periods of occupation were equally highly infected, and this is probably due to the lifestyle adopted by these populations. Hugot et al. (1999) suggested that pinworm infection in Ancestral Pueblo sites correlated with the architecture style adopted by each period of occupation, with the early occupations presenting the lowest prevalences and the recent occupations, the highest. Reinhard et al. (2016) also consider this hypothesis. However, in the present study, the results indicate that all periods of occupation and styles of habitation were highly infected by pinworms.

Humidity in habitations could have been a key feature that promoted pinworm transmission. The increased humidity of rooms, compared with the surrounding desert, can be felt in intact rooms, such as those along the back wall of Aztec Ruins West Ruin. It would be worthwhile to measure the humidity within these rooms compared with the outside humidity to get a baseline figure for the inherent potential of Pueblo room construction in humidifying the Pueblo environment. The humidity trapped in multistoried Pueblos of 100 rooms could have been substantial. Rooms used for communal activity such as kivas, mealing rooms, cooking areas, and sleeping areas could have made ideal pinworm nidi.

At the peak of its occupation, Salmon Ruins had 300 people living in the Great House, which have approximately 250 rooms. Not all of the rooms were used as habitation, since they also had ritual, burial, and storage functions. This fact leads us to presume that people 
congregated in these rooms, thus facilitating the airborne kind of transmission. Rituals happened in plazas or in kivas. Kivas are round constructions with ventilation systems. Time spent inside a kiva probably contributed to the spread of pinworm infection in this population. The same can be said about Aztec Ruins, despite the fact that the second occupation did not use the West Ruins Great House as habitation. This site was inhabited by between 700 and 1000 people (Lister and Lister 1987). The ritual constructions continued to be used, thus facilitating pinworm transmission and maintenance.

Other factors that need to be discussed are the hygiene habits adopted by these populations. Previous observed pinworm prevalence for Salmon Ruins raised this discussion. Pinworm epidemiology is correlated to temperate climate and to hygiene habits. Bathing and frequency of clothing change are cited as protective against pinworm infection (Rey 2008). In Salmon Ruins, Bohrer (1980) speculated on the production of soaps by Salmon Ruins inhabitants using Yucca roots. All other components of this plant were found in this site, except for the roots, thus leading to this hypothesis. The higher pinworm prevalence found in the recent study suggests that hygiene habits were maybe not as good as we thought, at least when considering pinworm transmission. Maybe this population simply chose to use Yucca roots for other purposes or not use it at all. The fact is that the conception of hygiene in this population was modified by the recent study.

We believe that earlier Basketmaker II pithouses would have served as a nidi for infection as described for kivas. The pithouses, like kivas, were designed to promote air circulation via smoke holes, deflectors, and air drafted in from the antechamber. As habitations for extended families, these structures would have made all people susceptible to airborne and person person contact.

Our data indicate that the most highly infected individuals may have experienced impaired health (Roberts et al. 2013). Roberts et al. (2013) mention that highly infected individuals can present ulcerations in the intestine due to the activity of adults to the tissue, leading to inflammation and bacterial infection; damage in the perianal area due to scratching; dermatitis due to the presence of eggs in this region; and complications due to worm migration to the vagina, uterus, and oviducts that can cause the formation of granulomas and lead to infertility. 
The VMR analysis indicates that pinworms were aggregated in these Ancestral Pueblo populations. This distribution is generally found in modern parasitological studies (Bush et al. 1997; Crofton 1971; Rózsa et al. 2000), and the identification of the same pattern found in these ancient populations suggests that these data can be compared. This indicates that all environmental and cultural determinants for pinworm infection, as discussed in the present study, can be applicable in modern epidemiological studies. These observations mean that possibly other ancient epidemiological studies on other infections could also be considered to help understand the modern epidemiology on emergence and reemergence of infections.

\section{Conclusion}

As noted in the "Introduction" section, the publication of this volume represents the completion of 50 years of research. We believe that our work foreshadows a new revolution in archeological parasitology. This revolution is based on accurate quantification, reliance on parasite ecology principles, application of parasite statistical methods, and refined archeological analysis of past lifestyles. This method will result in an understanding of parasite transmission control patterns in remote periods and extinct lifestyles. With the participation of archeologists and paleopathologists, we will be able to assess how well people adapted to infection through behaviors that controlled or exacerbated parasite infection.

Acknowledgments - The authors would like to acknowledge Fundação Carlos Chagas Filho de Amparo à Pesquisa do Estado do Rio de Janeiro, FAPERJ, the Pathoecology Laboratory, School of Natural Resources, University of Nebraska-Lincoln, the Harold W. Manter Laboratory of Parasitology, University of Nebraska-Lincoln, for providing logistical support, the San Juan County Archeological Research Center and Library and the Aztec Ruins National Monument New Mexico for allowing the collection of samples from Salmon Ruins and Aztec Ruins, respectively and for providing all support to our study. 


\section{References}

Bohrer VL (1980) Salmon ruin ethnobotanical report. In: Irwin-Williams C, Shelly PH (eds) Investigations at the Salmon site: the structure of Chacoan society in the northern southwest. Texas A\&MUniversity, Department of Anthropology, Texas, pp 163-351

BryantVM, Reinhard KJ (2012) Coprolites and archaeology: the missing links in understanding human health. In: HuntA, Milàn J, Lucas SG, Spielmann JA (eds) Vertebrate coprolites, bulletin 57. New Mexico Museum of Natural History \& Science, Albuquerque, pp 379-387

Bush AO, Lafferty KD, Lotz JM, Shostak AW (1997) Parasitology meets ecology on its own terms: Margolis et al. revisited. J Parasitol 83(4): 575-583. https://doi. org/10.2307/3284227

Callen EO, Cameron TWM (1960) A prehistoric diet as revealed in coprolites. New Sci 8(190):35-40

Camacho M, Araújo A, Morrow JJ, Reinhard KJ (2018a) Recovering parasites from mummies and coprolites: an epidemiological approach. Parasit Vectors 11:248. https://doi.org/10.1186/s13071-018-2729-4

Camacho M, Iñiguez AM, Reinhard KJ (2018b) Taphonomic considerations on pinworm prevalence in three ancestral Puebloan latrines. J Archaeol Sci 20:791-798. https://doi.org/10.1016/j.jasrep.2018.06.024

Crofton HA (1971) A quantitative approach to parasitism. Parasitology 62(2):179193. https://doi.org/10.1017/So031182000071420

Doyel DE (1992) Anasazi regional organization and the Chaco system. Maxwell Museum of Anthropology, Albuquerque

Dufour B, Le Bailly M (2013) Testing new parasite egg extraction methods in paleoparasitology and an attempt at quantification. Int J Paleopathol 3(3):199203. https://doi.org/10.1016/j.ijpp.2013.03.008

Fry GE (1977) Analysis of prehistoric coprolites from Utah. University of Utah Press, Salt Lake City

Fry GE (1980a) Prehistoric diet and parasites in the desert west of North America. In: Bowman D (ed) Early Native Americans.Moutin, The Hague, pp 325-339

Fry GE (198ob) Analysis of fecal material. In: Gilbert R, Mielke J (eds) The analysis of prehistoric diets. Academic Press, New York, pp 127-154

Fry GE, Hall H (1969) Parasitological examination of human coprolites from Utah. Proc Utah Acad Sci Art Letters 46:102-105 Fry GE, Moore JG (1969) Enterobius vermicularis: 10,0oo-year-old human infection. Science 166(3913):1620. https://doi.org/10.1126/science.166.3913.1620

Fugassa MH (2011) Paleoparasitological diagnosis. In: Ferreira LF, Reinhard KJ, Araújo A (eds) Foundations of Paleoparasitology. Editora FIOCRUZ, Rio de Janeiro, pp 223-254

FugassaMH, Reinhard KJ, Johnson KL, Gardner SL, VieiraM, Araújo A (2011) Parasitism of prehistoric humans and companion animals from Antelope Cave, Mojave County, Northwest Arizona. J Parasitol 97(5):862-867. https://doi. org/10.1645/GE-2459.1 
Hugot JP, Reinhard KJ, Gardner SL, Morand S (1999) Human enterobiasis in evolution: origin, specificity and transmission. Parasite 6(3): 201-208. https:// doi.org/10.1051/parasite/1999063201

Hulínská D (1974) Morphogenesis and viability of larvae in the eggs of Enterobius vermicularis. Folia Parasitol 21(3):225-232 Lister R, Lister F (1987) Aztec ruins on the animas: excavated, preserved, and interpreted. Southwest Parks and Monuments Association, Tucson

Ludwig JA, Reynolds JF (1988) Statistical ecology: a primer in methods and computing. John Wiley \& Sons, New York

Matson R, Chisholm B (1991) Basketmaker II subsistence: carbon isotopes and other dietary indicators fromCedarMesa, Utah.AmAntiq 56(3):444-459. https://doi.org/10.2307/280894

Moore JG, Fry GF, Englert E (1969) Thorny-headed worm infection in North American prehistoric man. Science 163(3873):1324-1325. https://doi. org/10.1126/science.163.3873.1324

Morrow JJ (2016) Exploring parasitism in antiquity through the analysis of coprolites and quids from La Cueva de los Muertos Chiquitos, Rio Zape, Durango, Mexico. University of Nebraska-Lincoln, Dissertation

Morrow JJ, Newby J, Piombino-Mascali D, Reinhard KJ (2016) Taphonomic considerations for the analysis of parasites in archaeological materials. Int J Paleopathol 13:56-64. https://doi.org/10.1016/j.ijpp.2016.01.005

Morrow JJ, Reinhard KJ (2016) Assessing the archaeoparasitological potential of quids as source materials for immunodiagnostic analyses. Korean J Parasitol 54(5):605-616. https://doi.org/10.3347/kjp.2016.54.5.605

Morrow JJ, Reinhard KJ (2018) The Paleoepidemiology of Enterobius vermicularis (Nemata: Oxyuridae) among the Loma San Gabriel at La Cueva de los Muertos Chiquitos (6oo-8oo CE), Rio Zape Valley, Durango, Mexico. Comp Parasitol 85(1):27-33. https://doi.org/10.1654/1525-2647-85.1.27

Pearsall DM (2016) Pollen analysis. In: Pearsall DM (ed) Paleoethnobotany, 3rd edn. Routledge Taylor and Francis Group, New York, pp 214-225

Rácz SE, Pucu de Araújo E, Jensen E, Mostek C, Morrow JJ, Van Hove ML, Bianucci R, Willems D, Heller F, Araújo A, Reinhard KJ (2015) Parasitology in an archaeological context: analysis of medieval burials in Nivelles, Belgium. J Archaeol Sci 53:304-315. https://doi.org/10.1016/j.jas.2014.10.023

Reiczigel J, Rózsa L (2005) Quantitative Parasitology 3.o. Budapest Reinhard KJ (1992) Patterns of diet, parasitism, and anemia in prehistoric West North America. In: Stuart-Macadam P, Kent S (eds) Diet, demography, and disease: changing perspectives on Anemia. Aldine de Gruyter, New York, pp 219-258

Reinhard KJ (2008a) Pathoecology of two ancestral Pueblo villages. In: Reitz EJ (ed) Case studies in environmental archaeology, 2nd edn. Plenum Press, New York, pp 191-209

Reinhard KJ (2008b) Parasite pathoecology of Chacoan Great Houses: The healthiest and wormiest ancestral Puebloans. In: Reed P (ed) Chaco's northern prodigies Salmon, Aztec, and the ascendancy of middle San Juan region after AD 1100. The University of Utah Press, Salt Lake City, pp 86-95 
Reinhard KJ (2017) Reestablishing rigor in archaeological parasitology. Int J Paleopathol 19:124-134. https://doi.org/10.1016/j.ijpp.2017.06.002

Reinhard KJ, Araújo A (2012) Synthesizing parasitology with archaeology in paleopathology. In: Buikstra J, Roberts C (eds) A global history of paleopathology. Oxford University Press, Oxford, pp 751-764

Reinhard KJ, Araújo A, Morrow JJ (2016) Temporal and spatial distribution of Enterobius vermicularis (Nemata: Oxyuridae) in prehistoric Americas. Korean J Parasitol 54(5):591-6o3. https://doi.org/10.3347/kjp.2016.54.5.591

Reinhard KJ, Araújo A, Sianto L, Costello JG, Swope K (2008) Chinese liver flukes in latrine sediments from Wong Nim's property, San Bernardino, California: archaeoparasitology of the Caltrans District headquarters. J Parasitol 94(1):300-303. https://doi.org/10.1645/GE-1049.1

Reinhard KJ, Bryant VM (2008) Pathoecology and the future of coprolite studies in bioarchaeology. Papers in Natural Resources, 205-224 Reinhard KJ, Buikstra $\mathrm{J}$ (2003) Louse infestation of the Chiribaya culture, southern Peru: variation in prevalence by age and sex. Mem Inst Oswaldo Cruz 98(1):173-179. https://doi. org/10.1590/So074-02762003000900026

Reinhard KJ, CamachoM, Geyer B, Hayek S, Horn C, Otterson K, Russ J (2019) Imaging coprolite taphonomy and preservation. Archaeol Anthropol Sci 11:6017-6035. https://doi.org/10.1007/s12520-019-00946-w

Reinhard KJ, Confalonieri UE, Herrmann B, Ferreira LF, Araújo AJG (1986) Recovery of parasite remains from coprolites and latrines: aspects of paleoparasitological technique. Homo 37(4):217-239

Reinhard KJ, Hevly RH, Anderson GA (1987) Helminth remains from prehistoric Indian coprolites on the Colorado Plateau. J Parasitol 73(3):630-639

Reinhard KR (1974) Relation of climate to epidemiology of infectious disease among Arctic populations. Alaska Med 16:25-30

Rey L (2008) Parasitologia - Parasitos e Doenças Parasitárias do Homem nos Trópicos Ocidentais. Guanabara Koogan, Rio de Janeiro

Roberts LS, Janovy J Jr, Nadler S (2013) Gerald D. Schmidt \& Larry S. Roberts' Foundations of Parasitology, McGraw-Hill International Edition, New York

Rózsa L, Reiczigel J, Majoros G (2000) Quantifying parasites in samples of hosts. J Parasitol 86(2):228-232. https://doi. org/10.1645/0022-3395(2000)086[0228:QPISOH]2.0.CO;2

Shaw D, Grenfell B, Dobson A (1998) Patterns of macroparasite aggregation in wildlife host populations. Parasitology 117(6):597-610

Vivian GR, Hilpert B (2012) The Chaco handbook: an encyclopedic guide. The University of Utah Press, Salt Lake City 